\title{
Coincident Activation of Metabotropic Glutamate Receptors and NMDA Receptors (NMDARs) Downregulates Perisynaptic/Extrasynaptic NMDARs and Enhances High- Fidelity Neurotransmission at the Developing Calyx of Held Synapse
}

\author{
Indu Joshi, ${ }^{*}$ Yi-Mei Yang, ${ }^{*}$ and Lu-Yang Wang \\ The Program for Neurosciences and Mental Health and Division of Neurology, The Hospital for Sick Children, and Department of Physiology, University of \\ Toronto, Toronto, Ontario, Canada M5G 1X8
}

\begin{abstract}
NMDA receptors (NMDARs) are usually downregulated in developing central synapses, but underlying mechanisms and functional consequences are not well established. Using developing calyx of Held synapses in the mouse auditory brainstem, we show here that pairing presynaptic stimulation with postsynaptic depolarization results in a persistent downregulation in the summated amplitude of NMDAR-mediated EPSCs (NMDAR-EPSCs) during a train of stimuli $(100 / 200 \mathrm{~Hz}, 100 \mathrm{~ms})$ at both $22^{\circ} \mathrm{C}$ and $35^{\circ} \mathrm{C}$. In contrast, the amplitude of single NMDAR-EPSCs or AMPA receptor-mediated EPSCs in the same synapses is not significantly altered, implying a preferential downregulation of perisynaptic/extrasynaptic NMDARs. Induction of this downregulation is blocked by antagonists for NMDARs or group I metabotropic glutamate receptors (mGluRs), suggesting that coincident activation of these two receptors is required. When the postsynaptic neuron is loaded with the fast $\mathrm{Ca}^{2+}$ buffer BAPTA or depolarized to $+60 \mathrm{mV}$ to reduce the driving force for Ca ${ }^{2+}$ influx, downregulation of the summated NMDAR-EPSCs is abolished, indicating $\mathrm{Ca}^{2+}$ plays a critical role in the induction. The expression of this downregulation depends on ongoing synaptic activity, and is attenuated by a dynamin peptide (D15) that blocks clathrindependent internalization. We further demonstrated that the same induction paradigm specifically reduces NMDAR-dependent plateau potential and aberrant spike firings during repetitive activity. Together, our results suggest that coincident activation of mGluRs and NMDARs during intense synaptic activity may lead to selective endocytosis of NMDARs in the perisynaptic/extrasynaptic domain, and implicate that mGluRs are potentially important for gating development of high-fidelity neurotransmission at this synapse.
\end{abstract}

Key words: calyx of Held-MNTB synapse; mGluRs; NMDA receptors; AMPA receptors; neurotransmission; spike firing; developmental plasticity

\section{Introduction}

During the critical period of development in sensory systems, synaptic strength and fidelity are profoundly modified by acute or chronic electrical activity (Constantine-Paton and Cline, 1998; Malenka and Bear, 2004). Numerous studies have shown that NMDARs are required for various forms of activity-dependent

Received June 15, 2006; revised July 24, 2007; accepted July 26, 2007.

This work was supported by an individual operating grant, "The Synapse" group grant from Canadian Institutes of Health Research, the Burroughs Wellcome Fund, and the EJLB Foundation (L-Y.W.). I.J. was a recipient of the Ontario Graduate Scholarship and the Hospital for Sick Children Research and Training Center Studentship. L-Y.W. holds a Tier II Canada Research Chair in Brain and Behavior. We thank Drs. John F. MacDonald and Michael W. Salter for valuable critiques and suggestions, Dr. Zhengping Jia for D15 and S15 peptides, and members of Wang laboratory for assistance and discussion.

*I.J. and Y-.M.Y. contributed equally to this work.

Correspondence should be addressed to Dr. Lu-Yang Wang, Division of Neurology, The Hospital for Sick Children,

555 University Avenue, Toronto, Ontario, Canada M5G 1X8. E-mail: luyang.wang@utoronto.ca.

I. Joshi's present address: Translational Pharmacology, Essen Instruments, Ann Arbor, MI 48108.

D0I:10.1523/JNEUROSCI.2506-07.2007

Copyright $\odot 2007$ Society for Neuroscience $\quad$ 0270-6474/07/279989-11\$15.00/0 plasticity in both developing and adult brains, despite the fact that NMDA receptor-mediated EPSCs (NMDAR-EPSCs) themselves may also undergo significant changes in size and kinetics after sensory experience (Carmignoto and Vicini, 1992; Hestrin, 1992; Takahashi et al., 1996; Constantine-Paton and Cline, 1998; Taschenberger and von Gersdorff, 2000; Cull-Candy et al., 2001; Futai et al., 2001; Joshi and Wang, 2002; Malenka and Bear, 2004). In a subset of fast synapses in the auditory system, namely the calyx of Held-principal neuron synapse in the medial nucleus of the trapezoid body (MNTB), NMDARs are present only transiently within the first two postnatal weeks (Taschenberger and von Gersdorff, 2000; Futai et al., 2001; Joshi and Wang, 2002). Because postsynaptic responses mediated by NMDARs in immature synapses have slow kinetics, repetitive activity can cause these responses to summate and produce a plateau potential, leading to a partial inactivation of voltage-gated channels. As a consequence, the ability of postsynaptic neurons to phase-lock spikes to presynaptic inputs is compromised, resulting in a break- 
down in the fidelity of spike timing critical for sound localization. To preserve this fidelity during high-frequency neurotransmission, it is proposed that NMDARs at these synapses have to be downregulated during early postnatal stages (Futai et al., 2001), but the mechanisms underlying this process remain unclear.

Using the developing calyx of Held-MNTB synapse in acute slices of the mouse auditory brainstem, we have explored potential mechanisms that may regulate the fate of synaptic and perisynaptic/extrasynaptic NMDARs around the postnatal stage when ear canals open and external sensory inputs start to take effect [postnatal day 10 (P10)-P13]. We found that bursts of presynaptic activity paired with postsynaptic depolarization could coincidently activate NMDARs and group I metabotropic glutamate receptors ( $m$ GluRs) and effectively downregulate perisynaptic or extrasynaptic NMDARs through clathrin-dependent internalization at this synapse, leading to the improved fidelity of high-frequency neurotransmission.

\section{Materials and Methods}

Brainstem slice preparation. Mice were housed in the facility certified by the Canadian Council of Animal Care and used for this study according to a protocol approved by the Hospital for Sick Children Animal Care Committee. As described previously (Forsythe and Barnes-Davies, 1993; Joshi and Wang, 2002), brainstem slices were prepared from P10-P13 mice (CD1/C57 black) except for older mice (P17-P19) used for experiments in Figure $1 D$. Mice were decapitated with a small guillotine and brains were dissected out and rapidly immersed in ice-cold artificial CSF (aCSF) containing (in $\mathrm{mm}$ ) $125 \mathrm{NaCl}, 2.5 \mathrm{KCl}, 10$ glucose, 1.25 $\mathrm{NaH}_{2} \mathrm{PO}_{4}, 2 \mathrm{Na}$-pyruvate, 3 myo-inositol, 0.5 ascorbic acid, $26 \mathrm{NaHCO}_{3}$, $1 \mathrm{MgCl}_{2}$, and $2 \mathrm{CaCl}_{2}$ at a $\mathrm{pH}$ of 7.3 when bubbled in $95 \% \mathrm{O}_{2}$ and $5 \%$ $\mathrm{CO}_{2}$. The brainstem was carefully dissected and then glued, rostral side up, to a stage used by the vibratome (VT1000S;Leica, Oberkochen, Germany) in a sectioning chamber, which was subsequently filled with icecold oxygenated aCSF. Approximately two or three transverse slices of the auditory brainstem (at the level of the seventh nerve) were cut sequentially at a thickness of $225-300 \mu \mathrm{m}$ and cautiously placed in an oxygenated incubation tray. The tray was then incubated in a water bath at $37^{\circ} \mathrm{C}$ for $1 \mathrm{~h}$, and kept at room temperature thereafter for experiments $\left(\sim 22^{\circ} \mathrm{C}\right)$

Electrophysiology: voltage- and current-clamp recording. Transverse slices were then transferred to a continuously perfused recording chamber mounted on an Olympus (Tokyo, Japan) microscope with Normarski optics and a $60 \times$ water-immersion objective. The perfusion solution consisted of oxygenated aCSF supplemented with bicuculline $(10 \mu \mathrm{M})$ and strychnine $(1 \mu \mathrm{M})$ to block inhibitory inputs and the flow rate was set at about $(1 \mathrm{ml} / \mathrm{min})$. A clip-like platinum bipolar stimulator electrode was placed near the midline of the slice for stimulation. Stimulation voltage was set at $20-30 \%$ above the threshold, unless otherwise stated. In all cases described for this study, all-or-none responses were recorded from individual MNTB neurons, indicating these responses originated from single calyx terminals. The perfusion barrel (a square glass pipette $\sim 400 \mu \mathrm{m}$ in width) was then gently placed onto the slice opposite to the stimulation electrode near the vicinity of clusters of MNTB cells to be recorded. The jet solution had a linear range of 1-2 $\mathrm{mm}$ and completely replaced the solution surrounding the recording region within 30-60 s. Whole-cell patch-clamp recordings were then made from visually identifiable postsynaptic MNTB neurons with an Axopatch 200B or Multiclamp 700A amplifier (Molecular Devices, Foster City, CA). The patch electrodes were pulled with the PP-830 electrode puller (Narishige, Tokyo, Japan) and had a resistance of $2-4 \mathrm{M} \Omega$. For voltage-clamp recordings, pipettes were filled with an intracellular solution containing (in mM) 97.5 K-gluconate, $32.5 \mathrm{CsCl}, 5 \mathrm{EGTA}, 10 \mathrm{HEPES}, 1 \mathrm{MgCl}_{2}$, $30 \mathrm{TEA}$, and 3 lidocaine $N$-ethyl bromide (QX314) (an intracellular blocker of $\mathrm{Na}^{+}$currents), $\mathrm{pH}$ 7.3. Series resistance for voltage-clamp recordings was 4-8 $\mathrm{M} \Omega$ and compensated to $90 \%$ with a lag of $10-15 \mu$ s. Holding potentials are given below and in the figures. For current-clamp recordings, $\mathrm{KCl}$ was used in place of $\mathrm{CsCl}$ in the intracellular solution whereas
TEA and QX314 were omitted. All recordings were performed with the fast-clamp mode $\left(I_{\text {fast }}\right)$ in cases where an Axopatch 200B amplifier was used. The resting potentials of MNTB neurons under our recording conditions were usually around $-65 \mathrm{mV}$ immediately after breakthrough, and small negative currents $(<100 \mathrm{pA})$ were often injected to achieve a membrane potential of $-70 \mathrm{mV}$ to facilitate comparison of firing patterns between cells with different resting potentials. For experiments in which pharmacological reagents were applied extracellularly, drugs were mixed into the bubbling aCSF and focally applied to the recorded cells using the fast perfusion system described above. Reagents were purchased from Sigma (St. Louis, MO), Tocris Bioscience (Ellisville, MO) and Alomone Labs (Jerusalem, Israel).

Data acquisition and analysis. Data were acquired online, filtered at 2 $\mathrm{kHz}$ and digitized at $10-50 \mathrm{kHz}$, and analyzed off-line with pClamp9 software (Molecular Devices). To quantify the amplitude of summated NMDAR-EPSCs in voltage-clamp recordings or that of plateau potential in current-clamp recordings during high-frequency trains, we visually determined the time point where the maximal amplitude relative to the baseline (before the onset of train stimuli) occurred, and then made all measurements and comparison at the same fixed time point for each synapse, as highlighted by double-headed arrows in trace examples throughout figures. To measure whole-cell current evoked by exogenous NMDA, we held MNTB neurons at $-20 \mathrm{mV}$ for 2 min before delivering ramps (from -60 to $+60 \mathrm{mV}$ ) (see Fig. $5 \mathrm{~B}$ ) for three times to measure passive and/or residual voltage-gated conductance. Subsequently, we applied NMDA $(100 \mu \mathrm{M})$ and repeated the same ramp paradigm three times after NMDA-evoked currents reached a maximum. The average ramp current in the absence of NMDA was digitally subtracted off-line from that in the presence of NMDA to obtain NMDAR-mediated ramp current, as displayed in Figure 5. All measurements of NMDA-evoked ramp current were made at $+60 \mathrm{mV}$, where a $15 \mathrm{~ms}$ step after ramp was incorporated into the voltage paradigm (see Fig. $5 B$ ) to allow reliable assay of the steady-state current (indicated by double-headed arrows). At a holding potential of $+60 \mathrm{mV}$, AMPA receptor (AMPAR)-mediated EPSCs (AMPAR-EPSCs) often ran up in amplitude within the first 10 min after breakthrough, likely because of a washout of endogenous spermine, which causes an inwardly rectifying current-voltage relationship (Joshi et al., 2004). Therefore, only the amplitude of AMPAR-EPSCs at $-60 \mathrm{mV}$ (where spermine has little effects on AMPARs) was quantified throughout this study. Averaged data are expressed as mean $\pm \mathrm{SE}$ and two-tailed Student's $t$ tests in Microsoft (Redmond, WA) Excel 2000 were done to determine significant differences $(p<0.05)$, as indicated with asterisks in figures.

\section{Results \\ Developmental downregulation of NMDARs is required for high-fidelity neurotransmission at the calyx of Held-MNTB synapse}

The calyx of Held-MNTB synapse is an axosomatic synapse capable of phase-locking postsynaptic spikes to presynaptic inputs at high rates (up to several hundred hertz). During development, biophysical changes in various voltage- and ligand-gated ion channels on presynaptic and postsynaptic elements converge to enable high-frequency neurotransmission (Trussell, 1999; von Gersdorff and Borst, 2002). To specifically ascribe the role of NMDARs in regulating the fidelity of neurotransmission, we first made voltage-clamp recordings of EPSCs from the calyx of HeldMNTB synapse in brainstem slices from two age groups of mice at $\mathrm{P} 10-\mathrm{P} 13$ or P16-P19. Figure $1, A$ and $B$, contrasts two voltageclamp recordings of EPSCs from P12 (left panel) and P18 (right panel) synapses in response to a single stimulus or a train of stimuli $(100 \mathrm{~Hz}, 100 \mathrm{~ms})$. For a P12 synapse at a holding potential of $+60 \mathrm{mV}$, where $\mathrm{Mg}^{2+}$ blockade of NMDARs is removed, a single stimulus typically evoked a fast AMPAR-EPSC followed by a slow NMDAR-EPSCs whereas a train of stimuli led to summated EPSCs as expected from slow decay kinetics of NMDAREPSCs (Wang, 2000; Joshi and Wang, 2002). In contrast, a P18 
A
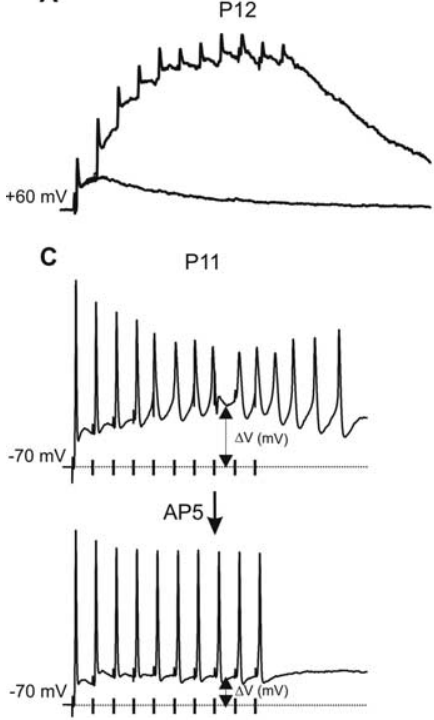

B

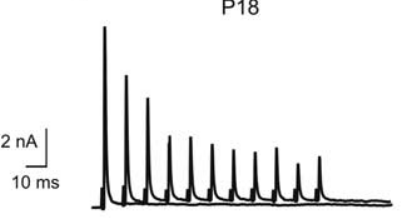

D

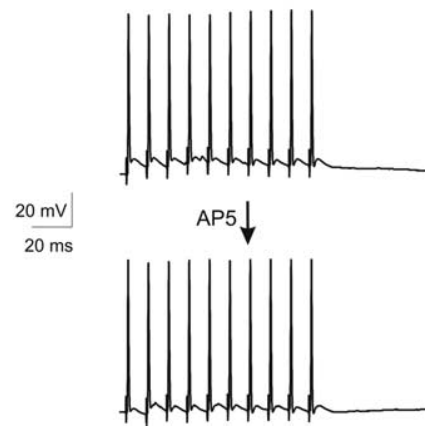

Figure 1. Developmental downregulation of NMDARs improves the fidelity of highfrequency neurotransmission. $A, B$, Examples of voltage-clamp recordings of EPSCs evoked by a single and a train of stimuli $(100 \mathrm{~Hz}, 100 \mathrm{~ms})$ from a P12 $(\boldsymbol{A})$ and a P18 synapse $(\boldsymbol{B})$. The holding potential (HP) for these recordings was $+60 \mathrm{mV}$ where both fast AMPAR-EPSCs and slow NMDAR-EPSCs are clearly distinguishable in P12 synapse, but only fast AMPAR-EPSCs are apparent in P18 synapse. $\boldsymbol{C}, \boldsymbol{D}$, Current-clamp recordings from P11 (C) and P18 (D) synapses of postsynaptic spikes in response to a train of stimuli $(100 \mathrm{~Hz}, 100 \mathrm{~ms}$, short vertical bars along the baseline mark the timing of stimuli) to the presynaptic axons before (top) and after (bottom) application of NMDAR antagonist $(\mathrm{D}, \mathrm{L})$-AP5 $(50 \mu \mathrm{m})$. Note that the irregular fluctuation of spike amplitude and aberrant off-phase firings in P11 synapse ( $\boldsymbol{C}$, top) are eliminated by AP5, converting the firing pattern of the P11 synapse to that reminiscent of the P19 synapse. Measurements of plateau potentials $(\Delta V)$ are graphically depicted and also described in Materials and Methods.

synapse, when stimulated with the same paradigms, exhibited neither a slow NMDAR component nor a summated response (Joshi and Wang, 2002). These observations confirmed that after the onset of functional hearing at P11/P12, NMDARs are downregulated to a minimal or undetectable level after $\mathrm{P} 16$, as reported previously (Futai et al., 2001; Joshi and Wang, 2002).

To define the physiological consequence of NMDAR downregulation, we made current-clamp recordings of spike firings driven by high-frequency synaptic activity $(100 \mathrm{~Hz}, 100 \mathrm{~ms})$ from these two populations of synapses. Figure $1 C$ (top) illustrates that the amplitude of action potentials fluctuated and underwent usedependent reduction after the first spike in a P11 synapse. Aberrant firings were observed after cessation of the stimulation train at this synapse (Fig. $1 C$ ) and also occurred in between evoked spikes in other synapses (see Fig. $7 A, B$, top). In contrast, little use-dependent reduction in spike amplitude was seen at a P18 synapse in response to the same stimulation train, and aberrant firings were entirely absent (Fig. $1 D$, top). Off-phase aberrant firings and use-dependent reduction in spike amplitude in P10$\mathrm{P} 13$ synapses can be attributed to the prominent plateau potential $(\Delta V=32.1 \pm 3.5 \mathrm{mV}$, relative to the membrane potential before stimulation), mostly resulting from summated activity of slow gating NMDARs during the train as demonstrated in Figure $1 A$. This was based on the observation that aberrant firings and usedependent reduction in spike amplitude during a train were alleviated after blocking NMDARs with (D,L)-AP5 $(100 \mu \mathrm{M})$ in these immature synapses (Fig. 1C, bottom), mimicking the firing pattern in P16-P19 synapses devoid of NMDARs (Fig. $1 D$, bottom). After application of AP5 to P10-P13 synapses $(n=4)$, the pla- teau potential was reduced to $\Delta V=11.9 \pm 0.8 \mathrm{mV}$, leading to a decline in aberrant firing ratio (i.e., the number of aberrant events normalized to the number of stimuli in a train) from $121.2 \pm 23.6 \%$ to $0 \%$, and an increase in the amplitude ratio of spikes generated by the 10th and first stimuli in the train from $21.4 \pm 5.8 \%$ to $75.4 \pm 2.7 \%$. These results clearly demonstrated that downregulation of NMDARs is a prominent form of plasticity necessary for the development of high-fidelity neurotransmission at the calyx of Held-MNTB synapse (Taschenberger and von Gersdorff, 2000; Futai et al., 2001; Joshi and Wang, 2002).

\section{Downregulation of NMDARs can be induced acutely by pairing tetanus bursts of presynaptic activity with postsynaptic depolarization}

During early postnatal development, NMDARs undergo agedependent downregulation after the onset of functional hearing at P11/P12, leading to the hypothesis that increased sensory activity may induce this downregulation. We therefore performed our experiments to test this hypothesis by measuring changes in EPSCs before and after a short period of intense synaptic activity in acute brainstem slices taken from developing mice within this critical age window (P10-P13). We have attempted various paradigms used for induction of long-term plasticity in other synapses and found that stimulation of presynaptic axons with tetanus bursts paired with depolarization of postsynaptic neurons was effective to induce persistent changes in NMDAR-EPSCs (Fig. 2A, pairing diagram). In each set of experiments, we first quantified basal AMPAR-EPSCs at $-60 \mathrm{mV}$ in response to single stimuli $(0.05 \mathrm{~Hz})$, and single and summated NMDAR-EPSCs evoked by a train of stimuli at $100 \mathrm{~Hz}$ by briefly holding the postsynaptic MNTB neuron at $+60 \mathrm{mV}$, where $\mathrm{Mg}^{2+}$ blockade of NMDARs is relieved (Fig. $2 \mathrm{~B}$ ). The main rationales for measuring summated NMDAR-EPSCs include the following: (1) because the NMDAR-dependent plateau potential (Fig. 1C) is most apparent during repetitive high-frequency activity, summated NMDAR-EPSCs represent the main physiological correlate underlying this potential; and (2) a single stimulus primarily activates synaptic NMDARs whereas a train of stimuli may also recruit perisynaptic or extrasynaptic NMDARs as a result of glutamate spillover in the calyceal terminal, which has several hundred release sites. By analyzing the amplitudes of the single NMDAR-EPSCs and the summated NMDAR-EPSCs, one may potentially gain insights into the fate of synaptic and perisynaptic or extrasynaptic NMDARs. In control experiments for quantifying basal synaptic responses without presynaptic and postsynaptic pairing, we alternated measurements of AMPAR-EPSCs at $-60 \mathrm{mV}$ and NMDAR-EPSCs at $+60 \mathrm{mV}$ every $3 \mathrm{~min}$ for $\sim 20$ min and found that these manipulations did not change the size of these EPSCs (see supplemental Fig. $1 A$, available at www.jneurosci.org as supplemental material).

When the presynaptic axon was stimulated with tetanus bursts for $1 \mathrm{~min}(50 \mathrm{~Hz} \times 60 \mathrm{~ms}$ or $100 \mathrm{~Hz} \times 30 \mathrm{~ms}$; interburst interval, $1 \mathrm{~s} ; 60$ bursts) paired with a postsynaptic depolarization to $-5 \mathrm{mV}$ (i.e., $20 \mathrm{mV}$ negative to the NMDAR reversal potential, approximately $+15 \mathrm{mV}$ ) (Fig. $2 \mathrm{D}$ ), we found that summated NMDAR-EPSCs at $+60 \mathrm{mV}$ underwent a time-dependent decrease in the size of plateau current during the test train, as shown by both the summary plot (Fig. $2 \mathrm{~B}$, left) and trace examples (Fig. $2 B$, right). Double-headed arrows in this and subsequent figures indicate the time point where the maximal amplitude of summated NMDAR-EPSCs was measured for individual synapses and compared throughout each experiment. Because of fast kinetics of individual AMPAR-EPSCs and robust synaptic depres- 
sion, cumulative activity of AMPARs during a train is unlikely to make a substantial contribution to the slow, summated NMDAR-EPSCs. Eighteen minutes after the onset of the pairing paradigm, the amplitude of summated EPSCs was decreased significantly to $58.9 \pm 3.8 \%$ of that before pairing $(p<0.05)$, whereas single NMDAR-EPSCs (at $+60 \mathrm{mV}$ ) and AMPAR-EPSCs (at $-60 \mathrm{mV}$ ) remained relatively stable over the same time course (Figs. 2B, 3D). In two synapses, selective downregulation of summated NMDAREPSCs persisted and was not reversed for up to $60 \mathrm{~min}$. In contrast, such a change in summated NMDAR-EPSCs was absent after the same presynaptic stimulation when postsynaptic neurons were held at potentials where NMDARs were largely blocked by $\mathrm{Mg}^{2+}$ (i.e., $-60 \mathrm{mV}, 98.7 \pm 4.7 \%$ at $t=$ 18 min; $n=3$ ) (Fig. 3D, supplemental Fig. $1 C$, available at www.jneurosci.org as supplemental material), implying that activation of NMDARs was required for inducing changes in summated NMDAREPSCs. With the same pairing paradigm, we were able to induce a persistent downregulation of summated NMDAR-EPSCs at near physiological temperature $\left(35^{\circ} \mathrm{C}\right)$, qualitatively similar to what was observed at room temperature $\left(\sim 22^{\circ} \mathrm{C}\right)$. The summated NMDAR-EPSCs during a $200 \mathrm{~Hz}$ train declined to $60.3 \pm 2.2 \%$ of that before application of the pairing paradigm. Again, neither the amplitude nor the current-voltage relationship of single NMDAR-EPSCs was significantly affected (Fig. 2C,E). We further compared the kinetics of single NMDAR-EPSCs before and after the pairing protocol and found no statistical difference in the time for these EPSCs to decay to $10 \%$ of peak values (39.5 $\pm 3.8 \mathrm{~ms}$ before vs $32.8 \pm 3.3 \mathrm{~ms} 15$ min after induction; $n=5$ ). The fact that summated NMDAR-EPSCs underwent downregulation after the induction paradigm whereas single NMDAR-EPSCs at $+60 \mathrm{mV}$ or single AMPAR-EPSCs at -60 $\mathrm{mV}$ remained relatively stable suggests that perisynaptic/extrasynaptic NMDARs are preferentially downregulated. In contrast, synaptic NMDARs and AMPARs are relatively less labile. Together, these results demonstrated that intense presynaptic activity and postsynaptic depolarization at both temperatures could selectively induce a reduction in the amplitude of summated NMDAR-EPSCs, likely through means that require activation of postsynaptic NMDARs.

\section{$\mathrm{Ca}^{2+}$ influx through NMDARs is required for activity- dependent downregulation of NMDARs}

To directly test the possibility that NMDAR activity during pairing was required for the induction of downregulation of summated NMDAR-EPSCs, we repeated the experiment where the same presynaptic stimulation with tetanus bursts was paired with postsynaptic depolarization $(-5 \mathrm{mV})$ while AP5 $(40 \mu \mathrm{M}$, a lower concentration to facilitate washout), a competitive antagonist for NMDARs, was added only for the induction period. After the slow washout of AP5 from slices, we found that the amplitude of summated NMDAR-EPSCs returned to prepairing levels $(107.5 \pm 5.9 \%$ at $t=18 \mathrm{~min} ; n=5$ ) (Fig. $3 A$ ), demonstrating that downregulation was prevented. AMPAR-EPSCs declined slightly in AP5, but this change was not statistically significant from those before pairing. Hence, selective activation of NMDARs is essential for induction of activity-dependent downregulation of summated NMDARs, but not AMPAR-EPSCs. We next questioned 
A Pre- and Post Pairing in AP5
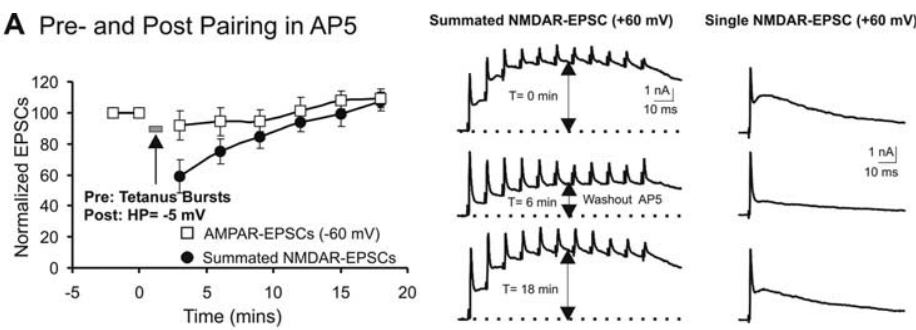

B Pre- and Post- Pairing in BAPTA
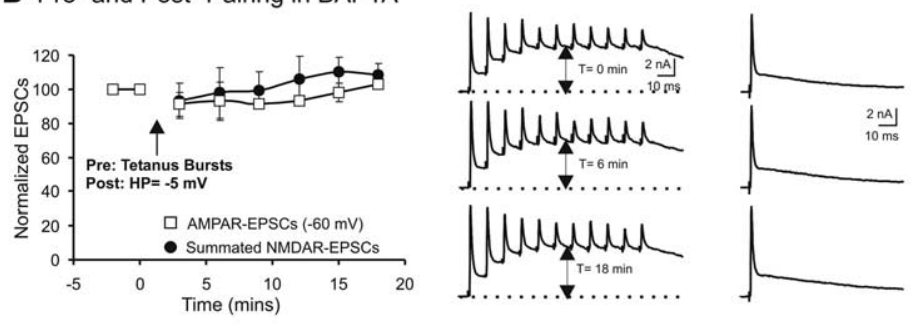

D

NMDAR-EPSCs (+60 mV)
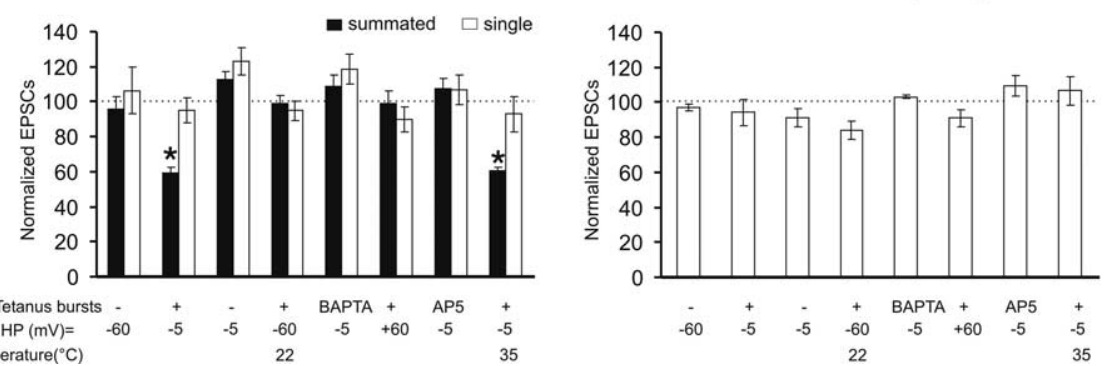

Figure 3. NMDAR activation and $\mathrm{Ca}^{2+}$ influx are required for inducing downregulation of summated NMDAR-EPSCS. $\boldsymbol{A}, \boldsymbol{B}$, Results of the same experiments as in Figure $2 B$ except for different experimental conditions [ $A$, NMDAR antagonist AP5 $(40 \mu \mathrm{M})$ was applied before and during the induction period; $\boldsymbol{B}$, postsynaptic neurons were preloaded with a fast $\mathrm{Ca}^{2+}$ buffer BAPTA (30 $\mathrm{mm})]$. In both cases, downregulation of summated NMDAR-EPS(s was attenuated. $C$, Summary of experimental observations from Figures 2, 3. See supplemental Fig. 1 (available at www.jneurosci.org as supplemental material) at $t=18 \mathrm{~min}$, showing that only pairing presynaptic tetanus bursts and postsynaptic depolarization to $-5 \mathrm{mV}$ induces a downregulation of summated NMDAEPSCs, but not single NMDAR-EPSCs (left) at $+60 \mathrm{mV}$, with little effects on AMPAR-EPSCs at $-60 \mathrm{mV}$ (right). The induction of this downregulation is dependent on $\mathrm{Ca}^{2+}$ influx through NMDARs. Results from 4 to 10 synapses in each set of experiments are pooled for plots of time course and bar graphs in Figure 2, 3 (see also supplemental Fig. 1, available at www.jneurosci.org as supplemental material). Asterisks indicate that the size of summated NMDAR (at either temperature) at $t=18$ min differs significantly from those under other experimental conditions (other filled bars).

whether $\mathrm{Ca}^{2+}$ influx through NMDARs during tetanus bursts was the key mediator of this downregulation. We loaded MNTB neurons with the same intracellular solution except that EGTA was replaced by the fast $\mathrm{Ca}^{2+}$ buffer BAPTA (30 mM) (Fig. 3B). After tetanus bursts paired with postsynaptic depolarization, downregulation of summated NMDAR-EPSCs was completely blocked (108.6 $\pm 6.5 \%$ at $t=18 \mathrm{~min} ; n=3$ ) (Fig. $3 B$, middle) whereas single EPSCs were unaltered (right), suggesting that $\mathrm{Ca}^{2+}$ influx is indeed required for the downregulation of NMDARs. Similarly, when $\mathrm{Ca}^{2+}$ inflow through NMDARs was minimized by depolarizing postsynaptic neuron to $+60 \mathrm{mV}$ to reduce the driving force for $\mathrm{Ca}^{2+}$ during the pairing period, downregulation of summated NMDARs was also blocked $(99.1 \pm 7.3 \%$ at $t=18 \mathrm{~min} ; n=4)$ (Fig. $3 D$, supplemental Fig. $1 B$, available at www.jneurosci.org as supplemental material). In the other two lines of control experiments, we held the postsynaptic MNTB at $-5 \mathrm{mV}$ for 1 min without pairing presynaptic tetanus stimuli, or at $-60 \mathrm{mV}$, but stimulated presynaptic axon with tetanus bursts and found little change in either NMDAR- or AMPAR-EPSCs (Fig. 3D, supplemental Fig. 1C, available at www.jneurosci.org as supplemental material). These results indi-
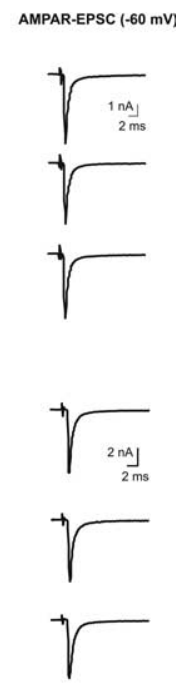

cated that neither postsynaptic depolarization nor presynaptic stimulation alone could induce NMDAR downregulation. Figure $3 D$ summarizes the results of single NMDA-EPSCs, summated NMDAREPSCs, and single AMPAR-EPSCs from different experimental conditions. These experiments clearly demonstrate that $\mathrm{Ca}^{2+}$ influx through postsynaptic NMDARs during tetanus bursts paired with postsynaptic depolarization is necessary for inducing persistent downregulation of summated NMDAR-EPSCs.

\section{Induction of activity-dependent downregulation requires coincident activation of NMDARs and group I mGluRs}

Given that the glutamate released during intense tetanus bursts may act on both ionotropic and metabotropic receptors (mGluRs), we next investigated whether mGluRs participated in induction of downregulating summated NMDAR-EPSCs. We first made use of two pharmacological antagonists for group I mGluRs (i.e., mGluR1 and mGluR5), 6-methyl-2(phenylethynyl)pyridine (MPEP; $10 \mu \mathrm{M}$; mGluR1-prefering antagonist) and (S)-(+)-a-amino-4-carboxy-2-methylbenzeneacetic acid (LY367385; $10 \mu \mathrm{M}$; mGluR5prefering antagonist). Because these reagents are not sufficiently specific to reliably differentiate mGluR1 and mGluR5, we used both reagents together to block group I mGluRs before the onset of pairing paradigm (Fig. 4A,B). We found that such pharmacological manipulations significantly attenuated downregulation of summated NMDAR-EPSCs (to $89.2 \pm 4.9 \%$ in MPEP and LY367385, $n=3$ vs $58.9 \pm 3.8 \%$ without blockers, $n=8 ; p<0.01)$ whereas single NMDAR-EPSCs and AMPAREPSCs remained unchanged (Fig. $4 B, C$ ). Indeed, another nonspecific mGluR antagonist, LY341495 [2S-2-amino-2-(1S,2S-2carboxycyclopropyl-1-yl)-3-(xanth-9-yl)propanoic acid, $5 \mu \mathrm{M}$, produced similar effects to those of MPEP and LY367385, and completely blocked downregulation of the summated NMDAREPSCs (99.6 $\pm 2.9 \%$ at $t=18 \mathrm{~min} ; n=6$ ) (Fig. 4B). Without pairing, application of MPEP and LY367385 $(n=3)$ had no effect on single and summated NMDAR-EPSCs $(96.6 \pm 7.5 \%$ and $95.1 \pm 2.0 \%$ at $t=18 \mathrm{~min}$, respectively) or single AMPAR-EPSCs $(98.9 \pm 1.4 \%)$, indicating there was little tonic activity of group I mGluRs (Fig. $4 B, C$ ). It has been shown that group I mGluRs are expressed in MNTB neurons and regulate transmitter release through presynaptic CB1 cannabinoid receptors (CB1Rs) (Kushmerick et al., 2004). To test whether downregulation of summated NMDAR-EPSCs involves CB1Rs, we applied the CB1R antagonist $\mathrm{N}$-(piperidin-1-yl)-5-(4-iodophenyl)-1(2,4-dichlorophenyl)-4-methyl-1H-pyrazole-3-carboxamide (AM251; $5 \mu \mathrm{M}$ ) before and during the induction paradigm. We found that downregulation of summated NMDAR-EPSCs was not affected ( $58.4 \pm 5.8 \%$ at $t=18 \mathrm{~min} ; n=3)$, indicating 


\section{A Summated NMDAR-EPSCs}
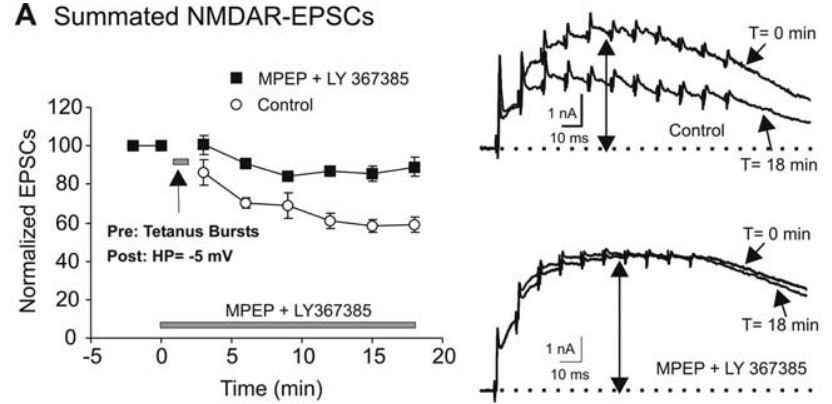

B

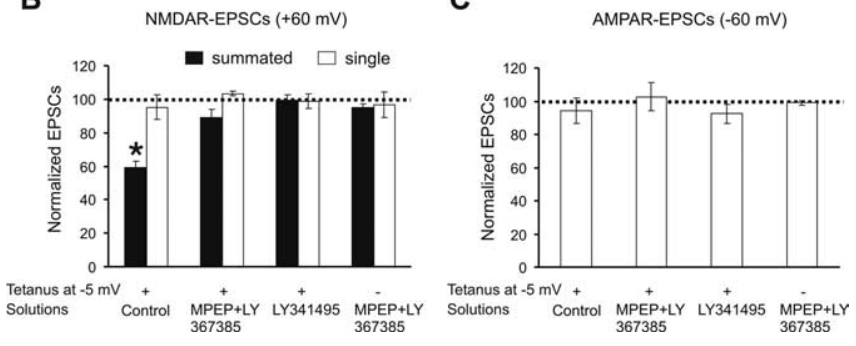

Figure 4. Group I mGluRs are required for inducing downregulation of summated NMDAREPSCS. A, Application of group I mGluR antagonists MPEP $(10 \mu \mathrm{M})$ and LY $367385(10 \mu \mathrm{M})$ before the pairing paradigm attenuated downregulation of summated NMDAR-EPSCS. Examples of summated EPSCs in control (top right) and mGluRs blockers (bottom right) are shown. $\boldsymbol{B}$, Plots of summated and single NMDAR-EPSCs at $+60 \mathrm{mV}$ after the pairing paradigm in control $(n=8)$ and with mGluR antagonists MPEP $(10 \mu \mathrm{M})$ and LY $367385(10 \mu \mathrm{m} ; n=3)$ or LY341495 $(5 \mu \mathrm{m} ; n=6)$. The last group of bars are from recordings in the presence of MPEP $(10 \mu \mathrm{M})$ and LY $367385(10 \mu \mathrm{m} ; n=3)$ without the pairing paradigm. C, Summary of the same experiments as in $\boldsymbol{B}$ except that AMPAR-EPSCs at $-60 \mathrm{mV}$ are plotted under all conditions. The asterisk indicates that the size of summated NMDAR at $t=18 \mathrm{~min}$ in control differs significantly from those in the presence of mGluR antagonists (other filled bars).

that CB1Rs are not required for the induction. Therefore, activity-dependent activation of group I mGluRs in postsynaptic neurons was required for the induction of persistent downregulation of summated NMDAR-EPSCs.

Because downregulation of NMDAR-EPSC required activation of postsynaptic mGluRs as well as depolarization to alleviate $\mathrm{Mg}^{2+}$ blockade of NMDARs, we next tested whether coincident activation of these two receptors was essential for initiating downregulation of NMDARs. Instead of using the pairing paradigm for induction, which might also activate presynaptic mGluRs/CB1Rs or postsynaptic AMPARs, we coapplied exogenous agonists for NMDARs and group I mGluRs to directly activate these receptors on postsynaptic neurons. As illustrated in Figure $5 A-C$, we alternated measurements of summated NMDAR-EPSCs at $+60 \mathrm{mV}$ (Fig. $5 C$ ) and ramp currents in NMDA (100 $\mu$ m; i.e., steady-state current at $+60 \mathrm{mV}$ ) (Fig. $5 B$, double-headed) (for details of ramp experiments, see Materials and Methods). These ramp currents not only allowed measurements of the size of NMDAR-mediated whole-cell currents, but also current-voltage relationships for these currents. Single AMPAR-EPSCs were again recorded at $-60 \mathrm{mV}$ in between these measurement time points. When NMDA alone was repeatedly applied to any given MNTB neuron, we observed a slight decline $(\sim 15 \%)$ in both NMDA ramp currents $(84.7 \pm 1.5 \%$ at $t=15$ $\min ; n=8$ ) and summated NMDAR-EPSCs at $+60 \mathrm{mV}$ (Fig. $5 C$ ) $(87.3 \pm 1.8 \%$ at $t=15 \mathrm{~min} ; n=8)$. Similarly, a brief application (1 min, after control measurements) of (RS)-3,5dihydroxyphenylglycine (DHPG; $100 \mu \mathrm{M}$ ) alone also had little effect on NMDA ramp current (Fig. 5B) $(87.3 \pm 1.8 \%$ at $t=15$ min; $n=6$ ). In contrast, when both NMDA and DHPG were coapplied during the induction phase, we found a robust reduction in NMDA ramp currents (to $47.2 \pm 4.2 \%$ at $t=15 \mathrm{~min} ; n=$ $3 ; p<0.05)$ and summated NMDAR-EPSCs were also significantly reduced (to $73.7 \pm 4.8 \%$ at $t=15 \mathrm{~min} ; p<0.05$ ) in the same cells. This reduction was not associated with any noticeable shift in the reversal potential of NMDAR-mediated currents, as judged from current-voltage relationships between -60 and $+60 \mathrm{mV}$. Application of antagonists for group I mGluRs, MPEP and LY367385, again attenuated the downregulation of NMDA ramp currents (to $71.0 \pm 6.6 \%$ at $t=15 \mathrm{~min} ; n=3$ ) and summated NMDAR-EPSCs (to $113.7 \pm 4.8 \%$ at $t=15 \mathrm{~min} ; n=3$ ) (Fig. $5 B, C$ ). These data suggested that coincident activation of postsynaptic NMDARs and mGluRs is necessary for the induction, and that the locus of expression of NMDAR downregulation resides in postsynaptic MNTB neurons. Noticeably, the extent of downregulation induced by coapplication of NMDA and DHPG was more pronounced for whole-cell NMDA ramp currents than for summated NMDAR-EPSCs. Again, single NMDAR-EPSCs remained unaltered under these conditions, reinforcing our interpretation that synaptic NMDARs and perisynaptic/extrasynaptic NMDARs might be differently regulated. These results are similar to those induced by presynaptic tetanus bursts paired with postsynaptic depolarization (Fig. 2). Subtle quantitative differences derived from these two induction paradigms may be explained by different accessibility of exogenous agonists versus endogenous glutamate spilled from terminal to perisynaptic/extrasynaptic NMDARs and mGluRs, or downstream spatial couplings between NMDARs and mGluRs in distinct subcellular domains (see Discussion).

\section{Expression of downregulation of NMDARs depends on ongoing synaptic activity}

After the induction phase with coapplication of NMDA and DHPG, we noted an immediate decrease in both NMDA ramp currents and summated NMDAR-EPSCs (Fig. $5 B, C$ ), but this decrease proceeded further as a function of time, implying that the expression of downregulation is use-dependent. To test this, we recorded both currents at the designated assay time points, in between which low-frequency stimuli $(0.05$ $\mathrm{Hz}$ ) were not given, as shown in Figure $5 D$ (diagram). Surprisingly, we found that NMDA ramp current displayed an immediate decrease in amplitude after the induction as in control, but no time-dependent decline thereafter $(79.6 \pm 10.9 \%$ at 15 min after induction; $n=4$ ), whereas further downregulation of summated NMDAR-EPSCs was completely absent (103.3 \pm $8.9 \%$ at $15 \mathrm{~min} ; n=4$ ) (Fig. $5 D$ ). These observations revealed that although coactivation of mGluRs and NMDARs was required for the induction, continual synaptic activity at low rates $(0.05 \mathrm{~Hz})$ in between assay points drove downregulation of NMDARs to proceed further. Because NMDA channels were mostly blocked in the presence of $\mathrm{Mg}^{2+}$ at a holding potential of $-60 \mathrm{mV}$ during low-frequency synaptic activity, we interpret this observation as such that continual binding of endogenously released glutamate to NMDAR and/or mGluRs or other unidentified cues may drive the progressive decline in NMDAR mediated currents. Collectively, these observations provided the direct evidence that mGluRs and NMDARs have to be concurrently activated for the induction of downregulation of NMDAR-mediated currents, but its expression depends on ongoing synaptic activity. 
A Induction paradigm with co-application of agonists for NMDAR and mGluRs

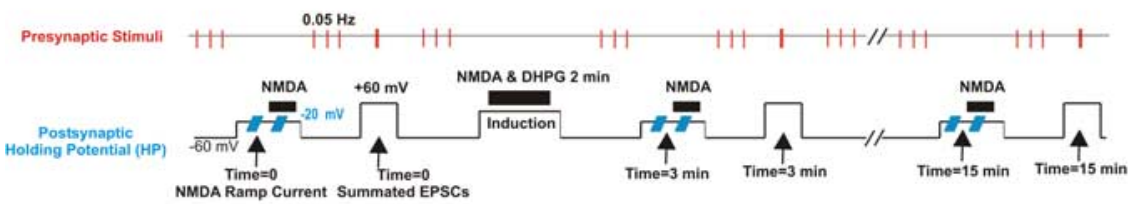

B NMDA ramp currents
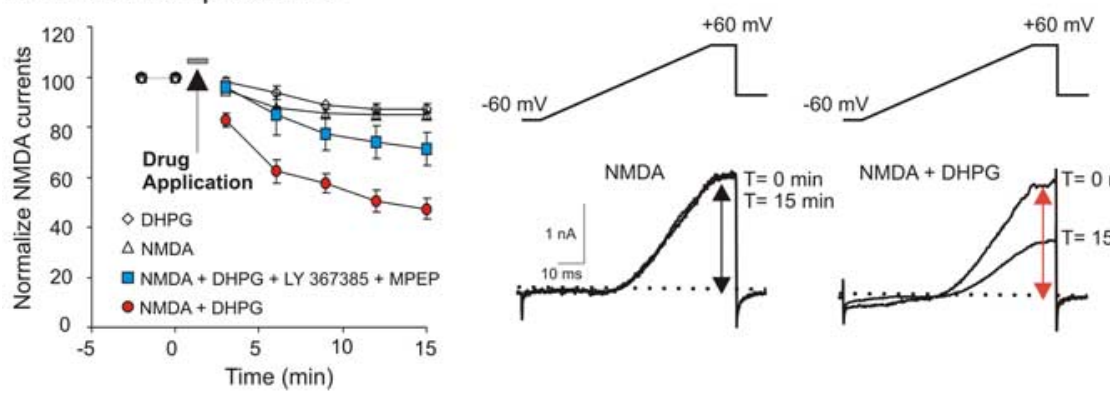

C Summated NMDAR-EPSCs
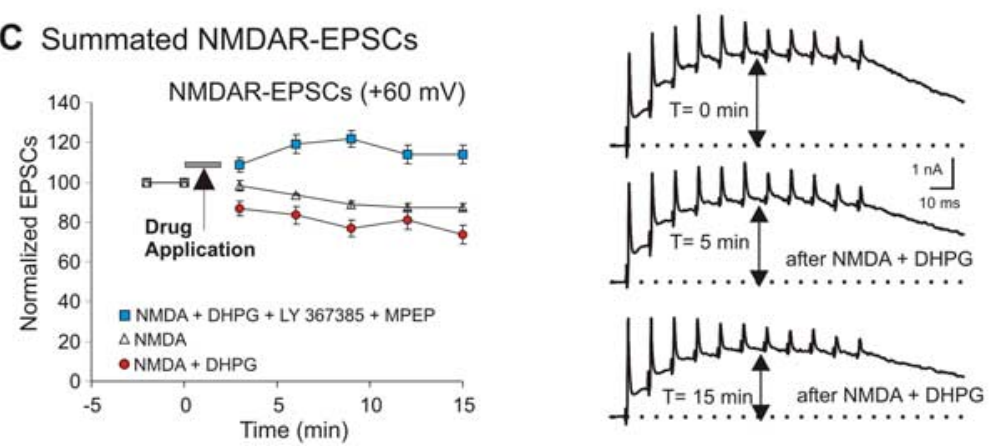

D With/without ongoing low frequency synaptic activity after induction
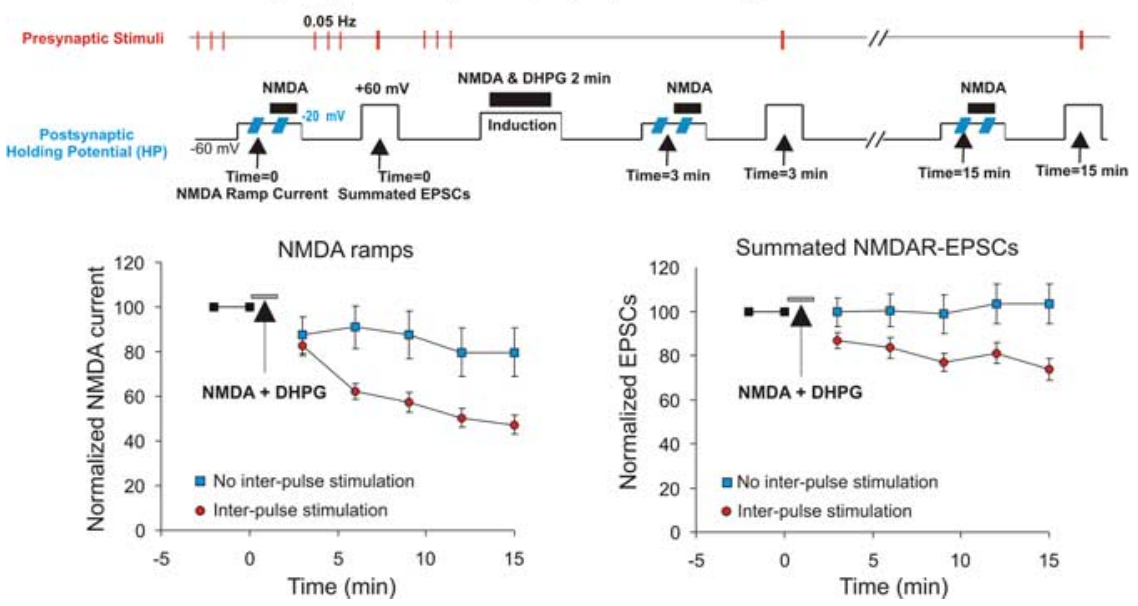

Figure 5. Downregulation of NMDARs requires coincident activation of group I mGluRs and NMDARs as well as ongoing synaptic activity. $\boldsymbol{A}$, Experimental paradigm illustrating coapplication of exogenous NMDA and mGluR agonist DHPG used for induction. Note that the detailed waveform of voltage ramp $(-60$ to $+60 \mathrm{mV})$ is given in $B$ and these ramps were repeated three times in the absence and presence of NMDA to allow subtraction of passive and/or residual currents from NMDAR-mediated currents. $\boldsymbol{B}$, Summary of normalized NMDA ramp currents at $+60 \mathrm{mV}$ in NMDA (100 $\mu \mathrm{m} ; n=8)$ or DHPG (100 $\mu \mathrm{M})$ alone $(n=6)$, coapplication of NMDA (100 $\mu \mathrm{M})$ and DHPG (100 $\mu \mathrm{m} ; n=3)$, and group I mGluR antagonists (MPEP, $10 \mu \mathrm{m} ; \mathrm{LY} 367385,10 \mu \mathrm{M}$, $n=3$ ) (left). Examples of NMDA ramp currents after application of NMDA alone (middle) or coapplication of NMDA and DHPG (right) are shown to illustrate changes in NMDA ramp currents (double-headed arrows indicate the time point where measurements were made). $\boldsymbol{C}$, Results of experiments as in $\boldsymbol{B}$ except that summated NMDAR-EPS(s at $+60 \mathrm{mV}$ are plotted for different conditions. Examples of summated NMDAR-EPSCs before and after coapplication of NMDA and DHPG are shown in the right panel. $D$, Same experiments as in $A$ except that low-frequency stimuli $(0.05 \mathrm{~Hz} ; n=4)$ were not given in between assay time points after the induction period, demonstrating that ongoing synaptic activity is required for the expression of downregulating both NMDA ramp currents (left) and summated NMDAR-EPSCs (right).
Clathrin-dependent internalization underlies activity-dependent downregulation of NMDARs

Knowing that coincident activation of mGluRs and NMDARs is critical for the induction of downregulation of NMDARs, we next explored the mechanism underlying the expression of this process. Emerging evidence suggests that glutamate receptors including NMDARs can be effectively internalized from cytoplasmic membrane by clathrin-dependent endocytosis (Collingridge et al., 2004; Kim and Sheng, 2004; Perez-Otano and Ehlers, 2005), a process that requires the GTPase activity of dynamin (Takei et al., 1996; Schmid et al., 1998). A common mechanism for the stimulation of dynamin GTPase activity is the promotion or stabilization of GDP and gamma phosphatedependent self-assembly of dynamin (Takei et al., 1996). By loading cells with GDP- $\beta$ S (0.6 mM), an inhibitor of GDP stabilization, we first examined the changes in NMDAR ramp currents and summated NMDAR-EPSCs after coactivation of NMDARs and mGluRs with the same paradigm as in Figure $5 A$. We found GDP- $\beta$ S effectively attenuated downregulation of both currents (NMDA ramp current, $74.2 \pm 3.1 \%$; summated NMDAEPSCs, $87.7 \pm 3.7 \%, 15 \mathrm{~min}$ after induction paradigm; $n=4$ ), suggesting that GTPase activity is indeed involved. Because hydrolysis of GTP to GDP is not only required for dynamin-dependent endocytosis, but also implicated in many other G-protein-dependent signaling processes, we next used another method to determine whether NMDARs were being specifically internalized through clathrinmediated endocytosis. We used a specific dynamin peptide composed of 15 aa (D15) that was known to interfere with the clathrin endocytotic complex and block internalization of membrane proteins including glutamate receptors during long-term depression (Lüscher et al., 1999; Man et al., 2000; Nong et al., 2003). We found that preloading D15 peptide $(2.5 \mathrm{mg} / \mathrm{ml}$, and proteinase inhibitor, $1 \mu \mathrm{l} / \mathrm{ml}$ ) into the postsynaptic cells effectively blocked downregulation of summated NMDAREPSCs induced by tetanus bursts paired with postsynaptic depolarization (91.8 \pm $6.9 \%$ at $18 \mathrm{~min}$ after induction; $n=5$ ) (Fig. 6A,C). In contrast, control peptide S15 containing the same amino acids as D15, but with scrambled sequence, failed to attenuate the downregulation of summated NMDAR-EPSCs $(61.1 \pm 4.0 \%$ at 18 min after induction; $n=7$ ), indistinguishable from the control group in which nei- 
ther peptide was added (Fig. $6 B, C$ ). Furthermore, neither treatment altered the single NMDAR-EPSCs at $+60 \mathrm{mV}$ or AMPAR-EPSCs at $-60 \mathrm{mV}$ (Fig. 6D). Together, these observations demonstrate that coincident activation of mGluRs and NMDARs leads to an internalization of NMDARs through clathrin-dependent endocytotic machinery, underlying the activity-dependent downregulation of summated NMDAR-EPSCs at the calyx of Held-MNTB synapse.

Activity-dependent downregulation of NMDARs reduces plateau potential and off-phase firings during high-frequency neurotransmission

To define the physiological consequence of NMDAR downregulation, we made current-clamp recordings of spike firings driven by high-frequency synaptic activity (Fig. 7A, $100 \mathrm{~Hz}, 100 \mathrm{~ms}, B, 300 \mathrm{~Hz}, 100$ $\mathrm{ms}$ ) before and after tetanus bursts of stimuli paired with postsynaptic depolarization. As described by Figure 1, we observed use-dependent reduction in the spike amplitude within stimulation trains and aberrant firings occurring between evoked spikes or after cessation of train stimuli (Fig. $7 A, B$, top). After the first spike, a prominent plateau potential built up as a result of summated activity of slow-gating NMDARs in a frequencydependent manner (i.e., 100 vs $300 \mathrm{~Hz}$ ) and led to incomplete repolarization and off-phase aberrant firings during and after the train. After pairing presynaptic stimulation with tetanus bursts $(100 \mathrm{~Hz} \times 30$ $\mathrm{ms}$, interburst interval $1 \mathrm{~s}, 60$ bursts) and postsynaptic depolarization $(-5 \mathrm{mV})$ for $1 \mathrm{~min}$ in voltage-clamp mode, we found that the plateau potential was reduced at both 100 and $300 \mathrm{~Hz}$, resulting in an elimination (Fig. $7 A, B$, example recording 1 , bottom left) or a reduction (Fig. $7 A, B$, example recording 2, bottom right) of aberrant firings. In all cases, use-dependent decreases in spike amplitude were alleviated (Fig. $7 \mathrm{~A}, \mathrm{~B}$, bottom). At $35^{\circ} \mathrm{C}$, qualitatively similar results were also obtained except that aberrant spikes were rarely observed (supplemental Fig. 2, available at www.jneurosci.org as supplemental material). When group I mGluRs were blocked with MPEP and LY367385, little change in firing patterns was induced (Fig. $7 C, D)$. Because cumulative activity of NMDARs mostly accounted for the plateau potential during the train, we determined the maximal plateau potential relative to the membrane potential before the stimulation train, and quantified time-dependent changes at $100 \mathrm{~Hz}$ (Fig. 7A) and $300 \mathrm{~Hz}$ (Fig. 7B) with or without addition of MPEP and LY367385. We found that pairing presynaptic tetanus bursts and postsynaptic depolarization led to a time-dependent decline in the normalized plateau potential (to $29.4 \pm 4.6 \%$ for $100 \mathrm{~Hz}$ and $33.9 \pm 5.1 \%$ for $300 \mathrm{~Hz}$ at $t=25 \mathrm{~min}$; $n=4)$, and this decline was blocked by antagonists for group I mGluRs $(91.6 \pm 7.6 \%$ for $100 \mathrm{~Hz}$ and $92.2 \pm 6.7 \%$ for $300 \mathrm{~Hz}$ at

\section{B S15}
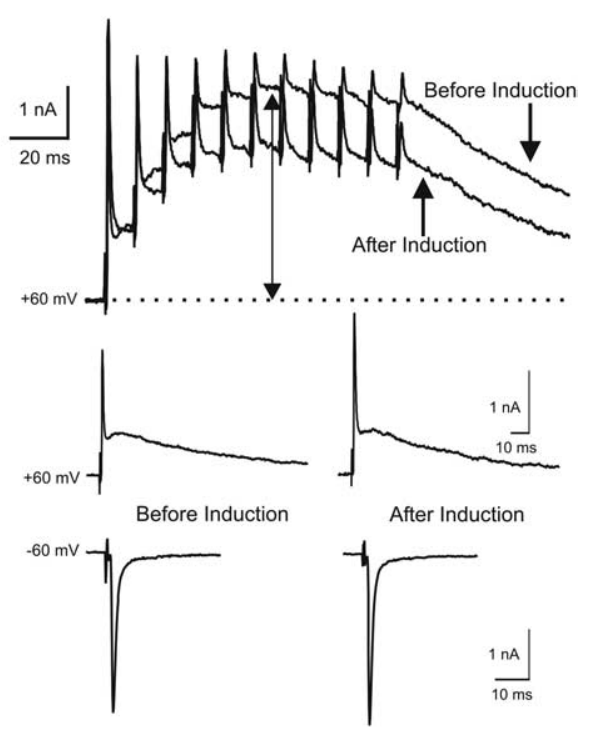

D Summary

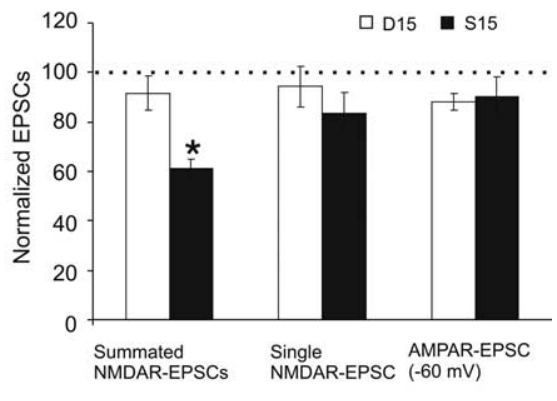

Figure 6. Clathrin-dependent endocytosis mediates removal of surface NMDARs. $\boldsymbol{A}, \boldsymbol{B}$, Example recordings of summated EPSCS at $+60 \mathrm{mV}$ (top) and single EPSCs at $\pm 60 \mathrm{mV}$ (middle, bottom) before and after the induction with pairing paradigm in the mented with proteinase inhibitor $(1 \mu \mathrm{l} / \mathrm{ml})$ loaded into postsynaptic cells. $C$. D Plots summarizing the time course and extent of changes in summated $(\boldsymbol{C})$ and single EPSCS $(\boldsymbol{D})$ with $\mathrm{S} 15(n=7)$ and D15 $(n=5)$. Note that neither treatment altered single NMDAR-EPSCs at $+60 \mathrm{mV}$ and AMPAR-EPSCs at $(-60 \mathrm{mV} ; p>0.05)$. The asterisk indicates significant difference in the amplitude of summated NMDAR-EPSCs between $\mathrm{D}_{15}$ and $\mathrm{S}_{15}$ groups at $t=18 \mathrm{~min}$.

$t=25 \mathrm{~min} ; n=4)$. To quantify the change in firing patterns, we counted the total number of aberrant spikes (in between timed spikes during and after $100 \mathrm{~ms}$ train) and spike failures (in response to timed inputs during the train) as a prepairing control, and used it as a reference index to calculate relative changes in aberrant firings after induction. We found that aberrant firings were significantly reduced from $100 \%$ before pairing to $11.7 \pm$ $5.7 \%$ at $100 \mathrm{~Hz}$ and $67.2 \pm 12.7 \%$ at $300 \mathrm{~Hz} 25 \mathrm{~min}$ after induction $(n=4)$, compared with $106.0 \pm 3.7 \%$ at $100 \mathrm{~Hz}$ and $105.9 \pm 11.0 \%$ at $300 \mathrm{~Hz}$ when MPEP and LY367385 were added. Finally, we used the amplitude ratio of spikes evoked by the 10th and first stimuli (for the $100 \mathrm{~Hz}$ train) or the 30th and first stimuli (for the $300 \mathrm{~Hz}$ train) to reflect changes in usedependent decline in spike amplitude and found that pairing induced significant increases in this parameter for both $100 \mathrm{~Hz}$ (from $43.3 \pm 11.0 \%$ to $76.4 \pm 1.7 \%$ ) and $300 \mathrm{~Hz}$ (from $45.2 \pm$ $11.5 \%$ to $73.4 \pm 5.1 \%$ ) whereas MPEP and LY367385 completely blocked such changes $(100 \mathrm{~Hz}, 51.4 \pm 10.8 \%$ before 


\section{A Control at $100 \mathrm{~Hz}$}
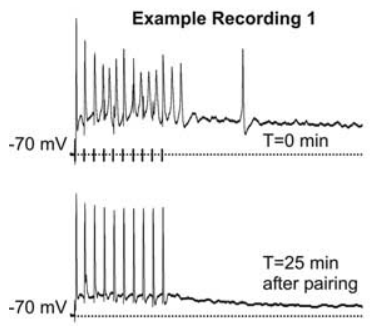

B Control at $300 \mathrm{~Hz}$
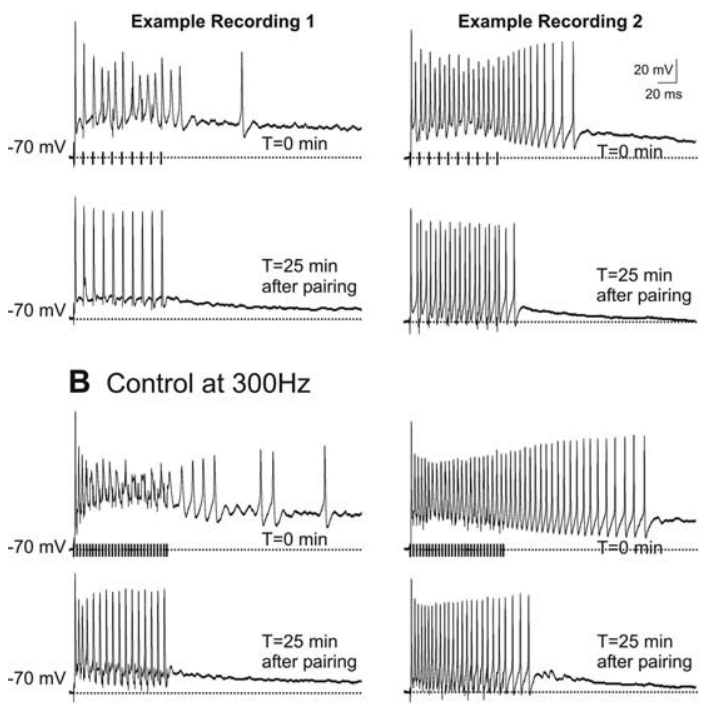

$\mathrm{T}=25 \mathrm{~min}$
after pairing

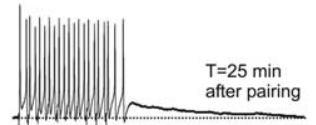

C mGluR blockers at $100 \mathrm{~Hz}$ $-70 \mathrm{~m}$

\section{D mGluR blockers at $300 \mathrm{~Hz}$}

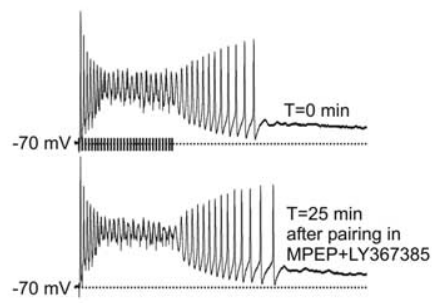

\section{E $100 \mathrm{~Hz}^{*} 100 \mathrm{~ms}$ trains}

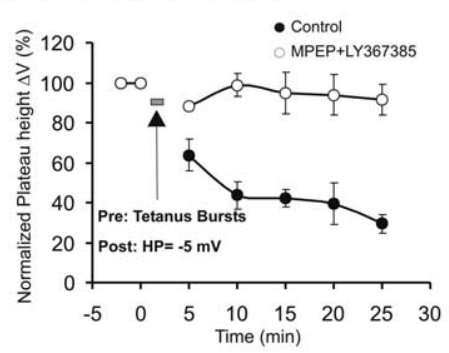

$\mathbf{F}$

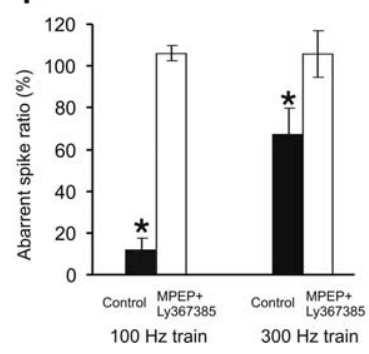

\section{G}

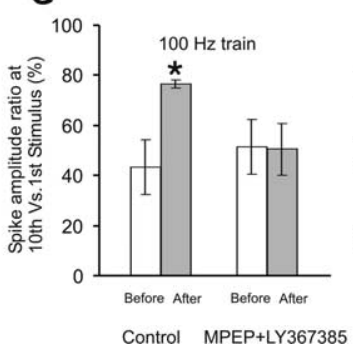

$300 \mathrm{~Hz}^{*} 100 \mathrm{~ms}$ trains

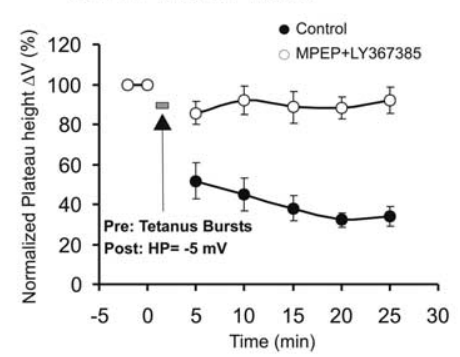

Figure 7. Downregulation of NMDARs improves the fidelity of high-frequency neurotransmission. $A-D$, Current-clamp recordings of postsynaptic spikes driven by high-frequency stimulation of presynaptic axons $(A, C, 100 \mathrm{~Hz}, 100 \mathrm{~ms} ; \boldsymbol{B}, \boldsymbol{D}, 300 \mathrm{~Hz}, 100 \mathrm{~ms})$ before and after pairing paradigm in two example cells from the control group $(\boldsymbol{A}, \boldsymbol{B})$ and in the presence of group I mGluR antagonists (MPEP, $10 \mu \mathrm{m}$; LY 367385, $10 \mu \mathrm{m} ; C$, D), showing that downregulation of plateau potentials during spike trains improves the fidelity of spikes, relieves use-dependent reduction of spike amplitude, and eliminates (as in example cell 1) or reduces (example 2) aberrant off-phase spikes. Short vertical bars along the baseline mark the timing of stimuli. $\boldsymbol{E}$, The height of plateau potentials (left) during the spike train (left, $100 \mathrm{~Hz}, 100 \mathrm{~ms}$; right, $300 \mathrm{~Hz}, 100 \mathrm{~ms}$ ) at different time points after the pairing paradigm were normalized to those before induction in the absence $(n=4)$ or presence of group I mGluR antagonists $(n=4)$ and plotted. Measurements of plateau potentials $(\Delta V)$ were the same as depicted in Fig. 1 or in Materials and Methods. $\boldsymbol{F}, \boldsymbol{G}$, Normalized aberrant spike ratio ( $\boldsymbol{F}$, including both aberrant spikes and spike failures in response to timed stimuli) and the amplitude ratio of the 10th or 30th evoked spike versus the first spike of the $100 \mathrm{~Hz}$ ( $\mathbf{G}$, left) or $300 \mathrm{~Hz}$ train (G, right) at $t=25 \mathrm{~min}$ were plotted to illustrate an improvement in the fidelity of evoked spikes and an alleviation of use-dependent reduction in spike amplitude. Both effects were prevented when group I mGluR antagonists were applied during induction pairing. The asterisks in $\boldsymbol{F}$ and $\boldsymbol{G}$ indicate significant difference between datasets of two neighboring columns.

and $50.5 \pm 10.3 \%$ after pairing; $300 \mathrm{~Hz}, 27.4 \pm 9.8 \%$ before to $26.6 \pm 9.2 \%$ after pairing). These observations provide compelling evidence that coincident activation of mGluRs and NMDARs has a profound impact on the NMDAR-dependent plateau potential during high-frequency synaptic transmission, and ultimately on the fidelity of phase-locking spike firings across this synapse.

\section{Discussion}

During the first 3 weeks of postnatal development, the calyx of Held-MNTB synapse undergoes significant modifications in its structural and biophysical properties (von Gersdorff and Borst, 2002). These changes lead to a fast, efficient, and reliable synapse, across which signal degradation is minimized even at high rates of neurotransmission (Trussell, 1999; von Gersdorff and Borst, 2002). Downregulation of NMDAR-EPSCs is certainly among these most important adaptations, because a reduction in NMDAR-EPSCs decreases the likelihood of aberrant firings. However, this developmental process likely takes several days (P11/P12 P17/P18) to complete in vivo after the onset of functional hearing. We showed here that acute stimulation of the presynaptic axon with tetanus bursts paired with postsynaptic depolarization in vitro for $1 \mathrm{~min}$ could immediately induce changes in synaptic responses that are somewhat reminiscent of those that have been observed in vivo. Although our observations support the view that external sensory activity after P11/P12 may drive the removal of NMDARs from postsynaptic MNTB neurons, it should be pointed out that our pairing paradigm for induction of downregulation of NMDARs presents much stronger stimuli than physiological cues in vivo. After the opening of external ear canals, gradual maturation of upstream synaptic connections and/or neuronal excitability may constrain the downstream intensity of pairing activity that the calyx of Held synapse experiences and, hence, developmental time course of NMDAR downregulation in vivo.

Although the calyx of Held-MNTB synapse is becoming a prominent model for studying synaptic transmission and short-term plasticity (von Gersdorff and Borst, 2002), a lack of long-lasting, activity-dependent plasticity thus far has placed it as a specialized model preparation. In this study, we described a novel form of persistent plasticity that displays quite different features from classical long-term depression (LTD) in other central synapses. The requirements for induction of downregulation of NMDARs and underlying expression mechanisms (i.e., internalization) at this synapse are similar to those for mGluR-dependent LTD (mGluR-LTD) of AMPARand NMDAR-EPSCs in hippocampus (Constantine-Paton and Cline, 1998; Collingridge et al., 2004; Malenka and Bear, 2004). However, several aspects of NMDAR downregulation at the calyx of Held-MNTB synapse are unique. In hippocampal CA1 synapses, mGluR-LTD induced by theta burst, pair-pulse stimuli, or 
group I mGluR agonist DHPG decreases the amplitude of single NMDAR- and AMPAR-EPSCs. At the calyx of Held-MNTB synapse, we found that single NMDAR- and AMPAR-EPSCs are surprisingly stable. Instead, by coincidently activating group I mGluRs and NMDARs, theta burst stimuli induce a selective downregulation of summated NMDAR-EPSCs. This downregulation is mediated by clathrin-dependent endocytosis of NMDARs solely, a process facilitated by low-frequency ongoing synaptic activity. In contrast, NMDARs and AMPARs appear to be tightly coupled in the internalization process at the hippocampal CA1 synapse (Snyder et al., 2001; Montgomery et al., 2005). Differences in morphological structures of the giant calyx synapse and typical small synapses may lead to different transmitter release and spillover profiles and, hence, preferential regulation of subpopulations of NMDARs. It remains to be tested whether perisynaptic/extrasynaptic NMDARs in classical bouton synapses can be selectively activated and downregulated by similar stimulation paradigms used in this study. Selective downregulation of summated NMDAR-EPSCs at the calyx of Held-MNTB synapse also differs from hippocampal LTD of NMDAR-EPSCs induced by a long low-frequency train ( $5 \mathrm{~Hz} ; 3 \mathrm{~min}$ ), which is dependent on protein phosphatase 1 and actin depolymerization, but not group I mGluR internalization (Selig et al., 1995; Morishita et al., 2005).

The most logical interpretation for selective downregulation of summated NMDAR-EPSCs, but not single NMDAR-/ AMPAR-EPSCs is that synaptic responses to a train of stimuli reflect activity of both synaptic and perisynaptic/extrasynaptic NMDARs, with the former being stably targeted to the postsynaptic density along with AMPARs, and the latter being highly mobile and readily subjected to activity-dependent trafficking. Although the exact subunit composition of NMDARs in MNTB neurons is not known (because of a lack of reliable antibodies for mice), it is possible that synaptic and perisynaptic/extrasynaptic NMDARs may differ (e.g., NR2A vs NR2B) and, hence, are subjected to differential modulation by activity. Alternatively, differential couplings of synaptic and perisynaptic/extrasynaptic NMDARs to group I mGluRs may affect dynamics of NMDAR trafficking at this synapse.

Responses mediated by NMDARs are usually potentiated by activation of mGluRs in different preparations (Kotecha and MacDonald, 2003), except for cases in which prolonged application of DHPG (5 min) in hippocampal slices led to an initial potentiation followed by a sustained depression as a result of NMDAR internalization (Snyder et al., 2001). We have shown that endogenous glutamate released during tetanus bursts can induce a rapid downregulation of NMDARs only under the condition that NMDARs and group I mGluRs are concurrently activated. Previous studies have shown that NMDARs are rather static relative to the turnover rate of AMPARs (Lissin et al., 1998; Carroll et al., 1999a,b; Lüscher et al., 1999; Ehlers, 2000; Man et al., 2000), however, recent evidence suggests that NMDARs are dynamic despite a limited understanding of regulatory mechanisms underlying the fate of NMDARs under physiological conditions (Roche et al., 2001; Snyder et al., 2001; Vissel et al., 2001; Fong et al., 2002; Li et al., 2002; Nong et al., 2003). Our study revealed that coincident activation of group I mGluRs and NMDARs can be one of the major mechanisms that dynamically regulate the fate of perisynaptic/extrasynaptic NMDARs in central synapses. In cultured or acutely isolated hippocampal neurons, which allow much more rapid solution exchange than slice preparation, it has been shown that timing of the activation of NMDARs and mGluRs is critical in determining the polarity and magnitude of changes in NMDA currents. As little as a few seconds apart between applications of two agonists for NMDARs and mGluRs may completely eliminate the action seen with simultaneous applications (Kotecha et al., 2003). Furthermore, our experiments with the dynamin peptide D15, implicated clathrindependent endocytosis as an effective pathway to remove surface NMDARs in perisynaptic/extrasynaptic sites. Although the precise mechanisms underlying how this coincident activation activates internalization machinery are yet to be determined, it is conceivable that strong spatial signaling or physical couplings between mGluRs and NMDARs may be important. In central synapses, previous studies have shown that group I mGluRs are usually localized in the perisynaptic/extrasynaptic domain (Lujan et al., 1997; Liu et al., 1998; Brasnjo and Otis, 2001). In fact, recent EM analyses of group I mGluRs in the rat calyx of HeldMNTB synapse have localized mGluRla exclusively to the postsynaptic MNTB neurons with particularly high concentration at perisynaptic/extrasynaptic sites (Kushmerick et al., 2004). We suggest that such a localization pattern provides subcellular substrates for effective interactions between mGluRs and NMDARs in perisynaptic/extrasynaptic domains. Furthermore, physical coupling between these receptors has been shown through postsynaptic density proteins such as Shank and Homer (Xiao et al., 2000; Kim and Sheng, 2004), raising the possibility that NMDARs and mGluRs can be cointernalized. In this study, we demonstrated that induction, but not expression of NMDAR downregulation, is strongly dependent on activation of NMDARs and subsequent $\mathrm{Ca}^{2+}$ influx. In MNTB neurons, AMPARs are devoid of the GluR2 subunit and, thus, are $\mathrm{Ca}^{2+}$. permeable. Tetanus burst activity presumably can provide robust $\mathrm{Ca}^{2+}$ influx through AMPARs themselves (Joshi et al., 2004), but fail to downregulate NMDARs (Fig. 2D, supplemental Fig. 1C, available at www.jneurosci.org as supplemental material). This suggests that induction of downregulation of NMDARs requires $\mathrm{Ca}^{2+}$ through NMDARs in a route-specific manner, and that only compartmentalized coupling between group I mGluRs and perisynaptic/extrasynaptic NMDARs (but not synaptic NMDARs and AMPARs) in postsynaptic neurons could selectively activate signaling cascade leading to internalization of NMDARs.

Although downregulation of NMDARs has been observed for a variety of synapses, functional consequences remain unclear. This study directly demonstrates that one of the physiological roles of downregulating perisynaptic/extrasynaptic NMDARs is to reduce the NMDAR-dependent plateau potential and enhance the fidelity of neurotransmission. Based on organization and trafficking rules of postsynaptic glutamate receptors (Kennedy and Ehlers, 2006), we suggest that sensory activity may promote coincident activation of mGluRs and NMDARs as the first step to phase out perisynaptic/extrasynaptic NMDARs, and then laterally drive synaptic NMDARs to perisynaptic/extrasynaptic endocytic zone for internalization. Additional experiments beyond the window of observation for this study (i.e., $20 \mathrm{~min}$ ) and/or other stimulation paradigms are required to test whether downregulation of synaptic NMDARs can be induced, as both perisynaptic/ extrasynaptic and synaptic NMDARs are downregulated in developing calyx of Held synapse in vivo. In conclusion, by being strategically positioned in the perisynaptic/extrasynaptic domain, group I mGluRs may serve as an ideal detector for sensory activity and gate developmental downregulation of NMDARs, and ultimately enable the phase-locking ability at this synapse. This is supported by the fact that downregulation of NMDARs is attenuated in mice whose sensory inputs are severed with bilat- 
eral cochlear ablation before the onset of hearing (Futai et al., 2001). In parallel with other presynaptic and postsynaptic adaptations converging onto reducing the plateau potential during development (Taschenberger and von Gersdorff, 2000; Futai et al., 2001; Joshi and Wang, 2002; von Gersdorff and Borst, 2002), downregulation of NMDARs gated by group I mGluRs may be potentially important for activity-dependent developmental plasticity at this auditory synapse and other central synapses.

\section{References}

Brasnjo G, Otis TS (2001) Neuronal glutamate transporters control activation of postsynaptic metabotropic glutamate receptors and influence cerebellar long-term depression. Neuron 31:607-616.

Carmignoto G, Vicini S (1992) Activity-dependent decrease in NMDA receptor responses during development of the visual cortex. Science 258:1007-1011.

Carroll RC, Lissin DV, von Zastrow M, Nicoll RA, Malenka RC (1999a) Rapid redistribution of glutamate receptors contributes to long-term depression in hippocampal cultures. Nature Neurosci 2:454-460.

Carroll RC, Beattie EC, Xia H, Luscher C, Altschuler Y, Nicoll RA, Malenka RC, von Zastrow M (1999b) Dynamin-dependent endocytosis of ionotropic glutamate receptors. Proc Natl Acad Sci USA 96:14112-14117.

Collingridge GL, Isaac JT, Wang YT (2004) Receptor trafficking and synaptic plasticity. Nat Rev Neurosci 5:952-962.

Constantine-Paton M, Cline HT (1998) LTP and activity-dependent synaptogenesis: the more alike they are, the more different they become. Curr Opin Neurobiol 8:39-148.

Cull-Candy S, Brickley S, Farrant M (2001) NMDA receptor subunits: diversity, development and disease. Curr Opin Neurobiol 11:327-335.

Ehlers MD (2000) Reinsertion or degradation of AMPA receptors determined by activity-dependent endocytic sorting. Neuron 28:511-525.

Fong DK, Rao A, Crump FT, Craig AM (2002) Rapid synaptic remodeling by protein kinase $\mathrm{C}$ : reciprocal translocation of NMDA receptors and calcium/calmodulin-dependent kinase II. J Neurosci 22:2153-2164.

Forsythe ID, Barnes-Davies M (1993) The binaural auditory pathway: excitatory amino acid receptors mediate dual timecourse excitatory postsynaptic currents in the rat medial nucleus of the trapezoid body. Proc Biol Sci 251:151-157.

Futai K, Okada M, Matsuyama K, Takahashi T (2001) High-fidelity transmission acquired via a developmental decrease in NMDA receptor expression at an auditory synapse. J Neurosci 21:3342-3349.

Hestrin S (1992) Developmental regulation of NMDA receptor-mediated synaptic currents at a central synapse. Nature 357:686-689.

Joshi I, Wang LY (2002) Developmental profiles of glutamate receptors and synaptic transmission at a single synapse in the mouse auditory brainstem. J Physiol (Lond) 540:861-873.

Joshi I, Shokralla S, Titis P, Wang LY (2004) The role of AMPA receptor gating in the development of high-fidelity neurotransmission at the calyx of Held synapse. J Neurosci 24:183-196.

Kennedy MJ, Ehlers MD (2006) Organelles and trafficking machinery for postsynaptic plasticity. Annu Rev Neurosci 29:325-362.

Kim E, Sheng M (2004) PDZ domain proteins of synapses. Nat Rev Neurosci 5:771-781.

Kotecha SA, MacDonald JF (2003) Signaling molecules and receptor transduction cascades that regulate NMDA receptor-mediated synaptic transmission. Int Rev Neurobiol 54:51-106.

Kotecha SA, Jackson MF, Al-Mahrouki A, Roder JC, Orser BA, MacDonald JF (2003) Co-stimulation of mGluR5 and N-methyl-D-aspartate receptors is required for potentiation of excitatory synaptic transmission in hippocampal neurons. J Biol Chem 278:27742-27749.

Kushmerick C, Price GD, Taschenberger H, Puente N, Renden R, Wadiche JI, Duvoisin RM, Grandes P, von Gersdorff H (2004) Retroinhibition of presynaptic $\mathrm{Ca}^{2+}$ currents by endocannabinoids released via postsynaptic mGluR activation at a calyx synapse. J Neurosci 24:5955-5965.
Li B, Chen N, Luo T, Otsu Y, Murphy TH, Raymond LA (2002) Differential regulation of synaptic and extra-synaptic NMDA receptors. Nat Neurosci 5:833-834.

Lissin DV, Gomperts SN, Carroll RC, Christine CW, Kalman D, Kitamur M, Hardy S, Nicoll RA, Malenka RC, von Zastrow M (1998) Activity differentially regulates the surface expression of synaptic AMPA and NMDA glutamate receptors. Proc Natl Acad Sci USA 95:7097-7102.

Liu XB, Munoz A, Jones EG (1998) Changes in subcellular localization of metabotropic glutamate receptor subtypes during postnatal development of mouse thalamus. J Comp Neurol 395:450-465.

Lujan R, Roberts JD, Shigemoto R, Ohishi H, Somogyi P (1997) Differential plasma membrane distribution of metabotropic glutamate receptors mGluR1 alpha, mGluR2 and mGluR5, relative to neurotransmitter release sites. J Chem Neuroanat 13:219-241.

Lüscher C, Xia H, Beattie EC, Carroll RC, von Zastrow M, Malenka RC, Nicoll RA (1999) Role of AMPA receptor cycling in synaptic transmission and plasticity. Neuron 24:649-658

Malenka RC, Bear MF (2004) LTP and LTD: an embarrassment of riches. Neuron 44:5-21.

Man HY, Lin JW, Ju WH, Ahmadian G, Liu L, Becker LE, Sheng M, Wang YT (2000) Regulation of AMPA receptor-mediated synaptic transmission by clathrin-dependent receptor internalization. Neuron 25:649-662.

Montgomery JM, Selcher JC, Hanson JE, Madison DV (2005) Dynamindependent NMDAR endocytosis during LTD and its dependence on synaptic state. BMC Neurosci 6:48.

Morishita W, Marie H, Malenka RC (2005) Distinct triggering and expression mechanisms underlie LTD of AMPA and NMDA synaptic responses. Nat Neurosci 8:1043-1050.

Nong Y, Huang YQ, Ju W, Kalia LV, Ahmadian G, Wang YT, Salter MW (2003) Glycine binding primes NMDA receptor internalization. Nature 422:302-307.

Perez-Otano I, Ehlers MD (2005) Homeostatic plasticity and NMDA receptor trafficking. Trends Neurosci 28:229-238.

Roche KW, Stanley S, McCallum J, Dune Ly C, Ehlers MD, Wenthold RJ (2001) Molecular determinants of NMDA receptor internalization. Nat Neurosci 4:794-802.

Schmid SL, McNiven MA, De Camilli P (1998) Dynamin and its partners: a progress report. Curr Opin Cell Biol 10:504-512.

Selig DK, Hjelmstad GO, Herron C, Nicoll RA, Malenka RC (1995) Independent mechanisms for long-term depression of AMPA and NMDA responses. Neuron 15:417-426.

Snyder EM, Philpot BD, Huber KM, Dong X, Fallon JR, Bear MF (2001) Internalization of ionotropic glutamate receptors in response to $\mathrm{mGluR}$ activation. Nat Neurosci 4:1079-1085.

Takahashi T, Feldmeyer D, Suzuki N, Onodera K, Cull-Candy SG, Sakimura K, Mishina M (1996) Functional correlation of NMDA receptor $\sigma$ subunits expression with the properties of single-channel and synaptic currents in the developing cerebellum. J Neurosci 16:4376-4382.

Takei K, Mundigl O, Daniell L, De Camilli P (1996) The synaptic vesicle cycle: a single vesicle budding step involving clathrin and dynamin. J Cell Biol 133:1237-1250.

Taschenberger H, von Gersdorff H (2000) Fine-tuning an auditory synapse for speed and fidelity: developmental changes in presynaptic waveform, EPSC kinetics, and synaptic plasticity. J Neurosci 20:9162-9173.

Trussell LO (1999) Synaptic mechanisms for coding timing in auditory neurons. Annu Rev Physiol 61:477-496.

Vissel B, Krupp JJ, Heinemann SF, Westbrook GL (2001) A use-dependent tyrosine dephosphorylation of NMDA receptors is independent of ion flux. Nat Neurosci 4:587-596.

von Gersdorff H, Borst JG (2002) Short-term plasticity at the calyx of Held. Nat Rev Neurosci 3:53-64.

Wang LY (2000) The dynamic range for gain control of NMDA receptormediated synaptic transmission at a single synapse. J Neurosci 20:RC115

Xiao B, Tu JC, Worley PF (2000) Homer: a link between neural activity and glutamate receptor function. Curr Opin Neurobiol 10:370-374. 